\title{
SINGLE-MANUFACTURER AND MULTI-RETAILER SUPPLY CHAIN MODEL WITH PRE-PAYMENT BASED PARTIAL FREE TRANSPORTATION
}

\author{
Amalesh Kumar Manna ${ }^{1}$, Rajan Mondal ${ }^{1}$, Ali Akbar Shaikh ${ }^{1, *}$, Irfan Ali ${ }^{2}$ and \\ Asoke Kumar Bhunia ${ }^{1}$
}

\begin{abstract}
In this paper, a supply chain model between a manufacturing firm and a group of retailers has been developed. Manufacturing firm produces simultaneously both perfect and imperfect items which are separated by screening process. Then the perfect items are transferred to the retailers' showroom/warehouse located in different places and a part of imperfect items are repaired by rework process. Retailers receive the products from the manufacturer with paying partial pre-payment to ensure the replenishment of order. On the other hand, the manufacturer provides partial free transportation facility to the retailers due to pre-payment. The corresponding problem has been formulated mathematically as a profit maximization problem and then solved it analytically. As an illustration of this supply chain model, three numerical examples have been considered and solved. Finally, post optimality analyses have been carried out to investigate the effects of changes of different parameters on the optimal policy.
\end{abstract}

Received February 9, 2020. Accepted April 5, 2021.

\section{INTRODUCTION}

In supply chain management, generally single-manufacturer and multi-retailer are involved in a system. Most of the manufacturing companies form a network with their retailers in order to sell their product by offering different facilities. Inventories take a crucial part to the manufacturer and retailer in supply chain system which involves different factors such as delivery systems, work in progress, cost reduction, etc. In 1968, Sherbrooke [35] wrote a book in this area considering single supplier and multiple retailers. Levi et al. [17] considered a single-warehouse multi-retailer problem with constant approximation algorithms. Sana [29] suggested a threelayer supply chain model where manufacturer produces both perfect and imperfect products. Furthermore, he considered Stakelberg approach in his model for comparing the integrated profit with the profit of whole chain. In the same year, Howard and Marklund [13] proposed an Economic Order Quantity (EOQ) model for multi-retailer with stochastic demand. Yang et al. [41] developed an optimal replenishment policies using genetic algorithm for multi-retailer system. At the same year, Yu et al. [42] also studied the multi-retailer problem for production system with stochastic demand. Pal and Mahapatra [25] developed single supplier, single manufacturer, single retailer oriented supply chain model where imperfect items are repaired by rework process. Also they considered stochastic demand and inspection errors for their model.

Keywords. Supply chain system, imperfect production, rework, pre-payment policy, transportation.

1 Department of Mathematics, The University of Burdwan, Burdwan 713104, India.

2 Department of Statistics \& Operations Research, Aligarh Muslim University, Aligarh 202002, India.

* Corresponding author: aakbarshaikh@gmail.com 
In the existing literature, it is observed that most of the inventory models were developed by considering the assumption that the buyer paid the total purchase cost of the products at the time of product delivery. However, in practice, there arise different possibilities for the payment of purchase cost: (i) payment be made at delivery time [20], (ii) facility of allowable partial delay-in-payment [5], (iii) partial pre-payment [38], and (iv) partial prepayment and allowable partial delay-in-payment [10]. The pre-payment is one of the safest and risk-less policy of the business for cash flow control. This pre-payment policy is proposed by manufacturer for monopoly business. Zhang [43] introduced pre-payment policy in a supply chain model. Taleizadeh [37] exhibited an EOQ model with pre-payment and partial backordering. Teng et al. [39] initiated pre-payment scheme in an inventory model for deteriorating items. After that, Diabat et al. [10] introduced partial pre-payment and delay-in-payment as well as partial backlogged shortage in an inventory model. Li et al. [18] presented advance-cash-credit payment scheme in inventory model for goods. After that, Shah et al. [32] analysed optimal replenishment time of the retailer for both the pre-payment and delay-in-payment. Khan et al. [15] studied pre-payment scheme in two warehouse system for deteriorating product. In the same year, Supakar and Mahato [36] proposed an inventory model with advance payment and uniform demand. They have used artificial bee colony algorithm for finding the optimal order quantity and maximum profit. Recently, Shaikh et al. [33] discussed a two-warehouse EOQ model with advance payment. They also determined the maximum backorder level and optimal order quantity by particle swarm optimization technique. In Table 1, a compact illustration of review of related literature to the proposed area of research has been presented.

In reality due to different reasons (viz. minor machinery problem, quality of raw-materials, deficiency of skill worker, etc.) a production system can not produce the perfect items fully. So at the time of production, some imperfect items along with perfect one are imminent. Rosenblatt and Lee [26] first reported about the imperfect production process. Ben-Daya and Hariga [2] exhibited an Economic Production Quantity (EPQ) model where production process is not perfect. Lin et al. [19] initiated inspection schedules in an integrated EPQ model for imperfect production process. Alfares and Ghaithan [1] developed EOQ and EPQ models with variable holding cost. Ouyang and Chang [24] studied an EPQ model for imperfect items with fully backlogging and allowable delay-in-payment. Bhunia et al. [6] analyzed an EPQ model for deteriorating items using genetic algorithm. Nobil et al. [23] investigated a production inventory problem in relating to the poultry firm. Later, Jain et al. [14] introduced a defective production inventory model considering time dependent demand in fuzzy environment. Manna et al. [22] incorporated inspection errors in a production inventory model where imperfect quality items are rectified by rework process. In addition, they have considered the demand dependent on warranty period and price of the product. Apart from, a number of imperfect production inventory models were developed by several researchers, viz. Salameh and Jaber [27], Goyal and Cárdenas-Barrón [11], Sana [28], Sarkar [30], Saroglu and Durmus [31], Tiwari et al. [40] and others.

To reduce the wastage and also to earn the maximum profit, some of the manufactures have intended rework policy for imperfect product. Hayek and Salameh [12] proposed rework policy for imperfect product in an optimal production lot size model. After that, Krishnamoorthi and Panayappan [16] proposed a production inventory model where imperfect items are converted to perfect items by the rework process. Bhunia et al. [6] established a production inventory model considering rework policy, interval-valued holding cost and variable demand. Manna et al. [21] developed an EPQ model with rework facility of defective products.

The remaining part of this paper is presented in different sections. In Section 2, research gap and contributions have been presented. Notation and assumptions have been presented in Section 3. The proposed model has been described mathematically in Section 4 and the solution procedure of the problem has been discussed in Section 5. Three numerical examples along with sensitivity analysis have been presented in Section 6 . In Section 7, practical implications of the proposed work have been discussed. Finally, conclusion of the proposed work along with suggestions for future investigations have been presented in Section 8 . 
TABLE 1. Summary of the literature, based on various assumptions related to the proposed model.

\begin{tabular}{|c|c|c|c|c|c|}
\hline Reported works & $\begin{array}{l}\text { Imperfect } \\
\text { production }\end{array}$ & $\begin{array}{l}\text { Rework } \\
\text { policy }\end{array}$ & Pre-payment & $\begin{array}{l}\text { Pre-payment based } \\
\text { free transportation }\end{array}$ & $\begin{array}{l}\text { Multi- } \\
\text { retailer }\end{array}$ \\
\hline Ben-Daya and Hariga [2] & $\sqrt{ }$ & $x$ & $x$ & $x$ & $x$ \\
\hline Bhunia and Shaikh [5] & $x$ & $x$ & $x$ & $x$ & $x$ \\
\hline Bhunia et al. [6] & $\sqrt{ }$ & $\sqrt{ }$ & $x$ & $x$ & $x$ \\
\hline Cárdenas-Barrón [7] & $\sqrt{ }$ & $\sqrt{ }$ & $x$ & $x$ & $x$ \\
\hline Diabat et al. $[10]$ & $x$ & $x$ & $\sqrt{ }$ & $x$ & $x$ \\
\hline Hayek and Salameh [12] & $\sqrt{ }$ & $\sqrt{ }$ & $x$ & $x$ & $x$ \\
\hline Howard and Marklund [13] & $x$ & $x$ & $x$ & $x$ & $\sqrt{ }$ \\
\hline Jain et al. [14] & $\sqrt{ }$ & $\sqrt{ }$ & $x$ & $x$ & $x$ \\
\hline Khan et al. [15] & $x$ & $x$ & $\sqrt{ }$ & $x$ & $\times$ \\
\hline Levi et al. [17] & $x$ & $x$ & $x$ & $x$ & $\sqrt{ }$ \\
\hline Li et al. [18] & $\times$ & $x$ & $\sqrt{ }$ & $x$ & $x$ \\
\hline Lin et al. $[19]$ & $\sqrt{ }$ & $x$ & $x$ & $x$ & $x$ \\
\hline Mallick et al. [20] & $\sqrt{ }$ & $\sqrt{ }$ & $x$ & $x$ & $x$ \\
\hline Manna et al. $[22]$ & $\sqrt{ }$ & $\sqrt{ }$ & $x$ & $x$ & $x$ \\
\hline Ouyang and Chang [24] & $\sqrt{ }$ & $\sqrt{ }$ & $x$ & $x$ & $x$ \\
\hline Pal and Mahapatra [25] & $\sqrt{ }$ & $\sqrt{ }$ & $x$ & $x$ & $x$ \\
\hline Rosenblatt and Lee [26] & $\sqrt{ }$ & $x$ & $x$ & $x$ & $x$ \\
\hline Sarkar [30] & $\sqrt{ }$ & $x$ & $x$ & $x$ & $x$ \\
\hline Sana [29] & $\sqrt{ }$ & $x$ & $x$ & $x$ & $x$ \\
\hline Shaikh et al. [33] & $x$ & $x$ & $\sqrt{ }$ & $x$ & $x$ \\
\hline Sherbrooke [35] & $x$ & $x$ & $x$ & $x$ & $\sqrt{ }$ \\
\hline Taleizadeh et al. [38] & $x$ & $x$ & $\sqrt{ }$ & $x$ & $x$ \\
\hline Taleizadeh [37] & $x$ & $x$ & $\sqrt{ }$ & $x$ & $x$ \\
\hline Teng et al. [39] & $x$ & $x$ & $\sqrt{ }$ & $x$ & $\times$ \\
\hline Yang et al. [41] & $x$ & $x$ & $x$ & $x$ & $\sqrt{ }$ \\
\hline Yu et al. [42] & $x$ & $x$ & $\times$ & $\times$ & $\sqrt{ }$ \\
\hline Zhang [43] & $x$ & $x$ & $\sqrt{ }$ & $x$ & $x$ \\
\hline Present work & $\sqrt{ }$ & $\sqrt{ }$ & $\sqrt{ }$ & $\sqrt{ }$ & $\sqrt{ }$ \\
\hline
\end{tabular}

\section{RESEARCH GAP AND CONTRIBUtion}

Firstly, some of the existing supply chain models were developed by several researchers with imperfect production [29], rework policy [25]. Again, several researchers viz. Taleizadeh [37], Supakar and Mahato [36], Shaikh et al. [33] proposed pre-payment policy in their established EOQ model. Yu et al. [42] proposed singlemanufacturer, multi-retailer supply chain model with generalized demand. Bhunia and Shaikh [3,4], Chung [8] Das et al. [9], Shaikh et al. [34] considered transportation cost to transport the order quantity from manufacturer to the retailers, but they did not connect with advanced payment policy. However, to the best of our knowledge, there is no previous work that covers single-manufacturer, multi-retailer supply chain problem for imperfect items under the concept of pre-payment based free delivery facility. For the first time this type of problem has been investigated and solved it analytically. Table 1 compares the properties of the reviewed inventory models based on five different features, viz. (i) imperfect production process, (ii) rework policy, (iii) pre-payment policy, (iv) pre-payment based transportation facility, (v) multiple retailers.

In this paper, a partial pre-payment based free transportation facility in single-manufacturer and multiretailer supply chain system has been studied. It is assumed that manufacturer produces perfect as well as imperfect items. A part of imperfect items is repaired by rework process which will reduce the wastage as well as manufacturer's production cost of the items. The manufacturing firm sells the perfect items to multiple retailers. Retailers prepay a fraction of the purchase cost to the manufacturer before the replenishment of 
items. Manufacturer waives a part of transportation cost to the retailers due to partial pre-payment. Finally, three different numerical examples have been considered for analyzing the effects of partial pre-payment, fully pre-payment and no pre-payment policy in the proposed supply chain system.

\section{Notation And ASsumptions}

To formulate the model mathematically, the following notation and assumptions have been considered and presented in Sections 3.1 and 3.2.

\subsection{Notation}

P: $\quad$ Production rate

$\theta: \quad$ Fraction of imperfect products produced/unit time

$\delta: \quad$ Fraction of imperfect items which are reworked

$n$ : $\quad$ Number of deliveries during the period of production

$m$ : Number of deliveries after the period of production

$r: \quad$ Total number of retailers

$Q_{j}: \quad$ Order quantity of $j$ th retailer per cycle, $j=1,2, \ldots, r$

$Q: \quad$ Total order quantity of all retailers in each cycle, where $Q=\sum_{j=1}^{r} Q_{j}$

$A$ : $\quad$ Set-up cost of manufacturer per production cycle

$c_{p}: \quad$ Cost of production/unit

$s_{c}$ : Cost of screening/unit

$r_{c m}$ : Reworking cost for repairing of defective products/unit

$h_{c}$ : Holding cost for perfect quality products of manufacturer/unit/unit time

$s_{r}: \quad$ Selling price of perfect item of manufacturer/unit

$c_{t}$ : Transportation cost per unit from manufacturing firm to the retailers

$d_{m j}: \quad$ Distance of $j$ th retailer from the manufacturing firm

$\beta_{j}$ : $\quad$ Pre-payment portion of the purchase cost of $j$ th retailer

$I_{e}$ : $\quad$ Rate of interest

$k_{j}$ : $\quad$ Multiple instalment of pre-payment of $j$ th retailer in each cycle

$\xi: \quad$ Control parameter of transportation cost

$c_{t}$ : Transportation cost per unit

$c_{d}: \quad$ Disposal cost per unit

T: $\quad$ Production period

\subsection{Assumptions}

(i) This is a single-manufacturer, multi-retailer supply chain model. Manufacturer's production starts at time $t=0$ with rate $P$ and continues up to the time $t=T$.

(ii) During the production, some defective products are produced along with the perfect items. The defective rate is considered as constant. A part of defective products is repaired by rework process.

(iii) Manufacturer delivers the order quantity $Q=\sum_{j=1}^{r} Q_{j}$ to the retailers in the time of interval $\frac{T}{n}$.

(iv) The $i$ th retailer prepaid $\beta_{i}(<1)$ part of the purchasing cost to the manufacturer in $\left(k_{i}-1\right)$ multiple installments. The remaining part $\left(1-\beta_{i}\right)$ of the purchasing cost will be paid at the receiving time of items. Manufacturer earns an interest for this partial pre-payment amount.

(v) Manufacturer gives the opportunity to the retailers by providing a part of transportation cost to transport the order quantity from manufacturer to the retailers due to partial pre-payment of purchasing cost.

\section{Mathematical Formulation}

In this work, single-manufacturer, multi-retailer supply chain problem have been considered where manufacturer claims a partial pre-payment from his/her retailers at the time of placing an order by a retailer. The 


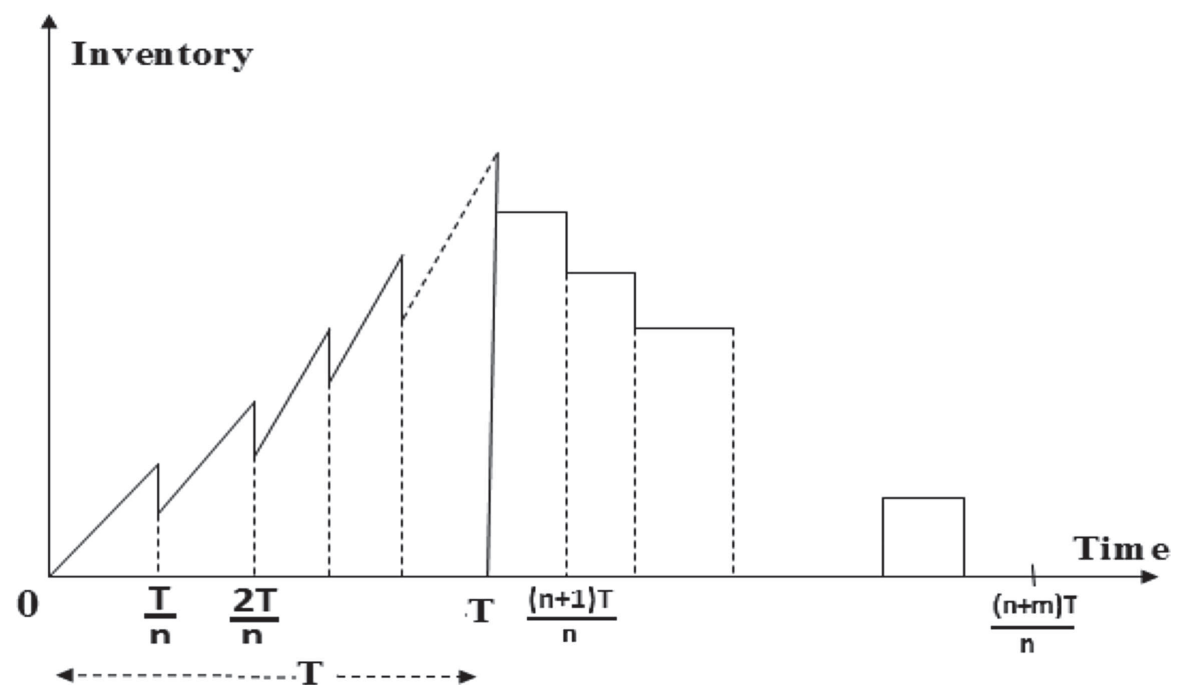

FigURE 1. Pictorial representation of manufacturer's inventory level of perfect items.

remaining part would be paid at the time of delivery. On the other hand, retailers decide to pay partial purchasing cost in $\left(k_{i}-1\right)$ equal installments. Moreover, for getting pre-payment from retailers, the manufacturer offers partial free transportation facility to them. As the manufacturing firm produces perfect items with a rate $(1-\theta) P$ and imperfect items at a rate $\theta P$. The manufacturing firm sells the perfect quality items only after screening and a part of imperfect items is repaired at a rate $\theta \delta P(0<\delta<1)$ during the production run time at a cost to restore its original quality. Manufacturer delivers a lot-size $(Q)$ in each cycle period. Different retailers receive their order and sell the items in their own markets. To examine the practicability of the proposed model, three numerical examples have been considered and solved. Then, in order to exhibit the effect of profit, post optimality analyses have been examined with respect to different system parameters. The pictorial representation of the inventory of perfect items is depicted in Figure 1.

Different costs, earning of sales revenue and average profit of the system have been elaborately discussed in the following subsections.

\subsection{Production, screening and reworking costs}

The production, screening and reworking costs per unit item are $c_{p}, c_{r s}$ and $r_{c m}$, respectively. Also the production rate, repairing rate and production period are $P, \theta \delta P$ and $T$ respectively. So the total cost for produced items, screening of perfect and imperfect items and reworking of imperfect items is given by

$$
\mathrm{PC}=\left\{c_{p}+s_{c}+r_{c m} \delta \theta\right\} P T .
$$

\subsection{Holding cost}

The total holding cost (cf. Fig. 1) is given by

$$
\begin{aligned}
\mathrm{HC} & =h_{c}\left[\frac{1}{2}\{(1-\theta) P+\theta \delta P\} T^{2}-\left\{\frac{T}{n}+\frac{2 T}{n}+\cdots+\frac{(n-1) T}{n}\right\} Q+\left\{\frac{T}{n}+\frac{2 T}{n}+\cdots+\frac{(m-1) T}{n}\right\} Q\right] \\
& =\frac{h_{c}}{2 n(m+n)}\{n(m+1)+m(m-1)\}\{(P-P \theta)+P \theta \delta\} T^{2} .
\end{aligned}
$$




\subsection{Transportation and setup costs}

Due to partial pre-payment, the manufacturer provides a part of transportation cost to the retailers to transport the product from manufacture to the retailers. In this regard, the cost of transportation in each batch is $c_{t} \sum_{j=1}^{r} \beta_{j}^{\xi} d_{m j} Q_{j}$, where $c_{t}$ is the unit transportation cost (which is spent by manufacturer) and $\xi(>1$ ) is the control parameter of transportation cost. So, the total transportation cost for $(m+n)$ cycle is given by

$$
\mathrm{TC}=(m+n) c_{t} \sum_{j=1}^{r} \beta_{j}^{\xi} d_{m j} Q_{j} .
$$

Also the set up cost per production cycle of manufacturer is $A$. So, the total set up cost of $n$ production cycle is given by

$$
\mathrm{CS}=n A .
$$

\subsection{Disposal cost}

As per assumption, a part of the imperfect items can not be repaired, it should be rejected. This is a loss of the manufacturer. In order to reduce the environmental pollution, the non-repairable items are to be destroyed. In this case, the total disposal cost for the entire cycle is given by

$$
\mathrm{DC}=c_{d}(1-\delta) \theta P T
$$

\subsection{Manufacturer's interest earned by pre-payment policy}

The $j$ th retailer pre-pays $\beta_{j}(<1)$ portion of purchasing cost to the manufacturer in $\left(k_{i}-1\right)$ multiple instalments. The remaining part $\left(1-\beta_{j}\right)$ of purchasing cost will be paid at the receiving time of items. So the interest earned by the manufacturer from this partial pre-payment amount is shown in Figure 2.

Now, the interest earned by the manufacturer in $i$ th cycle from $j$ retailer is given by

$$
\begin{aligned}
\mathrm{IE}_{i} & =I_{e}\left\{s_{r} \beta_{j} \frac{Q_{j}}{k_{j}} \times \frac{T}{n k_{j}}+s_{r} \beta_{j} \frac{Q_{j}}{k_{j}} \times \frac{2 T}{n k_{j}}+\ldots+s_{r} \beta_{j} \frac{Q_{j}}{k_{j}} \times \frac{\left(k_{j}-1\right) T}{n k_{j}}\right\} \\
& =\frac{s_{r} I_{e}}{2 n k_{j}} \beta_{j}\left(k_{j}-1\right) Q_{j} T .
\end{aligned}
$$

So, the total amount of interest earned due to pre-payment is given by

$$
\mathrm{IE}=(m+n) \sum_{j=1}^{r} \frac{s_{r} I_{e}}{2 n k_{j}} \beta_{j}\left(k_{j}-1\right) Q_{j} T .
$$

\subsection{Sales revenue}

Total sales revenue of the manufacturer is given by

$$
\mathrm{SR}=s_{r}\{(1-\theta) P+\delta \theta P\} T .
$$

\subsection{Manufacturer's profit}

Based on different components mentioned in (4.1)-(4.8), the total profit of the manufacturing firm is given by

$$
\mathrm{TP}(T)=\mathrm{SR}+\mathrm{IE}-\mathrm{PC}-\mathrm{HC}-\mathrm{TC}-\mathrm{DC}-\mathrm{CS} .
$$




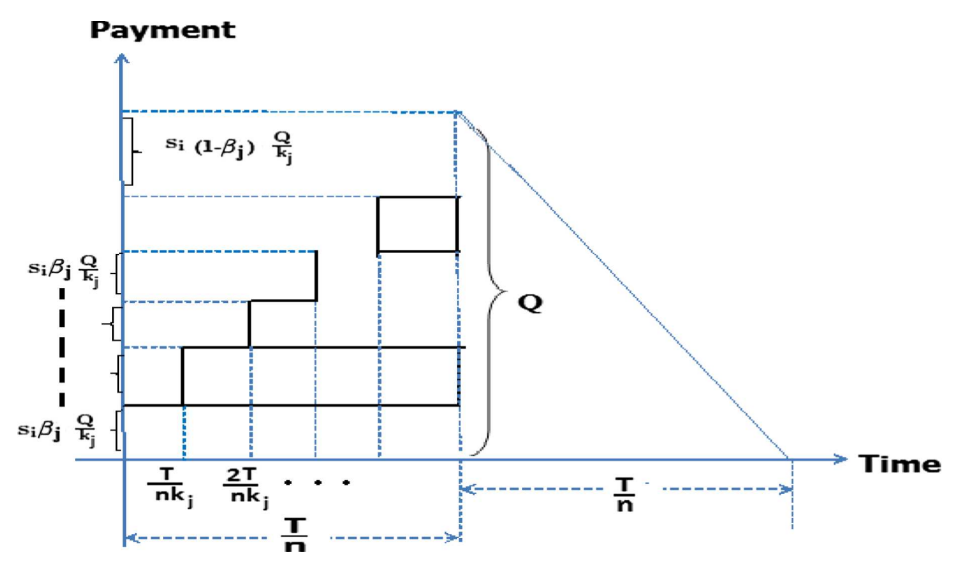

FiguRE 2. Pictorial representation of pre-payment policy of $j$ th retailer in each delivery.

So, the average profit of the manufacturing firm is given by

$$
\begin{aligned}
\Pi(T)= & \frac{\operatorname{TP}(T)}{\frac{1}{n}(m+n) T} \\
= & \frac{n P}{m+n}\left[s_{r}\{(1-\theta)+\theta \delta\}-\left\{c_{p}+s_{c}+r_{c m} \delta \theta+c_{d}(1-\delta) \theta\right\}\right]+s_{r} \sum_{j=1}^{r} \frac{I_{e}}{2 k_{j}} \beta_{j}\left(k_{j}-1\right) Q_{j} \\
& -\frac{h_{c}}{2(m+n)^{2}}\{n+m(n+m-1)\}\{(1-\theta)+\theta \delta\} P T-\frac{n c_{t}}{T} \sum_{j=1}^{r} \beta_{j}^{\xi} d_{m j} Q_{j}-\frac{n^{2} A}{(m+n) T} .
\end{aligned}
$$

\subsection{Objective of the proposed problem}

The goal of this work is to optimize the average profit $\Pi(T)$ of the manufacturing firm. Hence, the corresponding optimization problem is given by

$$
\begin{aligned}
& \text { Maximize } \Pi(T) \\
& \text { subject to } T>0 \text {. }
\end{aligned}
$$

This is a non-linear constrained maximization problem.

\section{Solution PROCEDURE}

The maximization problem (4.10) is a concave non-linear programming problem (the concavity of the objective function has been shown in Appendix). According to the optimality theory of a concave non-linear optimization problem, a local optimum $\left(T^{*}\right)$ of $(4.10)$ is a global optimum also and it is unique.

The necessary condition for optimality of $\Pi(T)$ is given by

$$
\begin{aligned}
& \frac{\mathrm{d}}{\mathrm{d} T}\{\Pi(T)\}=0 \quad \text { with } T>0 \\
& \Rightarrow-\frac{h_{c}}{2(m+n)^{2}}\{n+m(n+m-1)\}\{1-(1-\delta) \theta\} P+\frac{n c_{t}}{T^{2}} \sum_{j=1}^{r} \beta_{j}^{\xi} d_{m j} Q_{j}+\frac{n^{2} A}{(m+n) T^{2}}=0 \\
& \Rightarrow T=(m+n) \sqrt{\frac{2 n\left\{c_{t} \sum_{j=1}^{r} \beta_{j}^{\xi} d_{m j} Q_{j}+\frac{n A}{m+n}\right\}}{h_{c}\{n+m(n+m-1)\}\{1-(1-\delta) \theta\} P}} \quad \text { as } \quad T>0 .
\end{aligned}
$$


TABLE 2. Values of system parameters' related to retailers.

\begin{tabular}{lllll}
\hline \hline Retailer & $\begin{array}{l}\text { Demand } \\
\left(Q_{j} \text { unit }\right)\end{array}$ & $\begin{array}{l}\text { Pre-payment } \\
\text { portion }\left(\beta_{j}\right)\end{array}$ & $\begin{array}{l}\text { No. of instalments of } \\
\text { pre-payment }\left(k_{j}-1\right)\end{array}$ & $\begin{array}{l}\text { Distance from the } \\
\text { manufacturer }\left(d_{m j} \mathrm{~km}\right)\end{array}$ \\
\hline 1 & 17 & 0.70 & 6 & 20 \\
2 & 18 & 0.65 & 4 & 50 \\
3 & 11 & 0.55 & 9 & 30 \\
4 & 16 & 0.60 & 7 & 25 \\
5 & 19 & 0.80 & 8 & 15 \\
\hline
\end{tabular}

From the concavity of the objective function of (4.10), the sufficient condition for optimality of the same has been satisfied at $T$ given by (5.1). The systematic procedure for obtaining optimal solution of (4.10) has been given in the following steps:

Step 1. Set the suitable values of the input parameters $n, P, m, Q_{j}, \delta, \theta, \beta_{j}, k_{j}, c_{p}, s_{c}, r_{c m}, c_{d}, h_{c}, A, s_{r}, c_{t}$, $I_{e}, \xi, d_{m j}$ and $r$.

Step 2. Calculate the value of $T=T^{*}$ using (5.1).

Step 3. Calculate the value of average profit $\Pi\left(T^{*}\right)$.

Step 4. End.

\section{NumERICAL EXAMPLES}

In this section, three numerical examples have been considered to check the validity of the proposed model. These examples have been solved by analytical method and LINGO software.

Example 6.1. In this example, we have considered that the manufacture will pay a part of transportation cost to the retailers for transporting the product due to partial pre-payment. The values of different parameters of this example are taken as: $n=7, P=2000$ unit, $m=5, \theta=0.15, \delta=0.90, s_{r}=\$ 48, c_{p}=\$ 30, s_{c}=\$ 2$, $r_{c m}=\$ 12, c_{t}=\$ 0.4, c_{d}=\$ 1.5, h_{c}=\$ 3, A=\$ 50, I_{e}=0.08, \xi=14, r=5$. The parameters related to the retailers per delivery are given in Table 2.

It should be noted that the values of the parameters of the model are not selected from any case study, but realistic. Also, Figure 3 (plotted using MATLAB) represents the concavity of average profit of Example 6.1. The optimal value of the production period is $T^{*}=0.4276951$ year and the maximum average profit is $\Pi\left(T^{*}\right)=\$ 14909.66$.

Example 6.2. In this example, we have considered without partial pre-payment policy i.e., manufacture does not allow partial pre-payment facility and a part of transportation cost is not waived to his retailers to transport the product from manufacture to the retailer. The values of the parameters of this example are taken as the same of Example 6.1 except partial pre-payment parameters $\left(c_{t}, \xi, d_{m j}, \beta_{j}, j=1,2, \ldots, 5\right)$. The values of these mentioned parameters are taken as zero.

Solution. The optimal value of the production period is $T=0.4005891$ year and the maximum average profit is $\Pi\left(T^{*}\right)=\$ 14891.08$.

Example 6.3. In this example, we have considered that the manufacture paid a part of transportation cost to the retailers to transport the product from the manufacture to the retailers due to fully pre-payment. The values of the parameters of this example are taken as the same of Example 6.1 except partial pre-payment parameters $\left(\beta_{j}, j=1,2, \ldots, 5\right)$. The values of these mentioned parameters are taken as 1 i.e., $\left(\beta_{j}=1, j=1,2, \ldots, 5\right)$. 


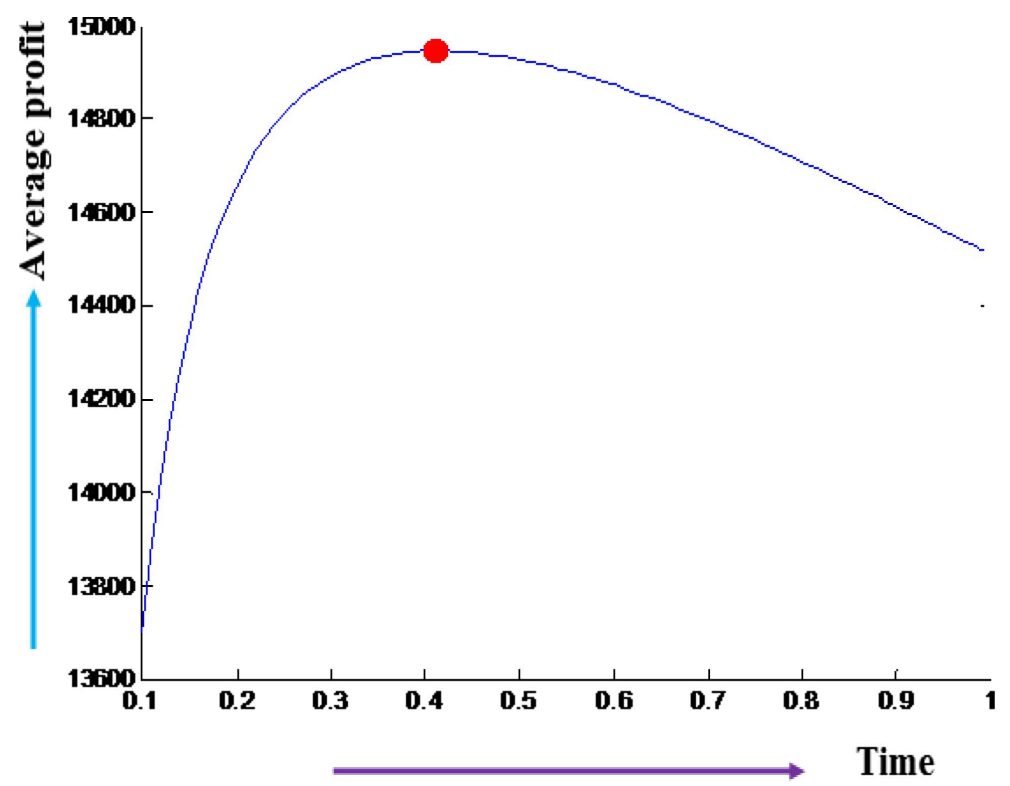

FIGURE 3. Geometrical representation of average profit with respect to $T$.

Solution. The optimal value of the production period is $T=2.263442$ year and the maximum average profit is $\Pi\left(T^{*}\right)=\$ 10281.04$.

Example 6.4. In this example, we have considered that the manufacture offers $r \%$ discount on selling price to the retailers due to pre-payment. Also manufacturer do not spend any cost for transport the purchase goods from manufacturers to the retailers. The values of the parameters of this example are taken as the same of Example 6.1 except $s_{r}$ and $c_{t}$. The values of these mentioned parameters are taken as $c_{t}=0$ and $s_{r}=(1-r) \times 48$, where $r=5 \%$.

Solution. The optimal value of the production period is $T=0.4247781$ year and the maximum average profit is $\Pi\left(T^{*}\right)=\$ 12196.41$.

\subsection{Discussion with comparison of examples}

Based on prepayment policy of manufacturer, three different types of numerical examples have been considered. In Example 6.1, partial pre-payment and waive of transportation cost have been considered. On the other hand, in Example 6.2, partial pre-payment facility is not allowed and a part of transportation cost is not allowed. Finally, fully pre-payment facility and transportation cost have been considered in Example 6.3. After solving all the examples, the following observations are found.

From Table 3, it is observed that the the average profit of Example 6.1 is greater than the average profit of Examples 6.2 and 6.3. So from the economical point of view, it is concluded that the manufacturer gain more profit in case of partial pre-payment based free transportation policy.

\subsection{Post optimality analyses}

In this subsection, post optimality analyses have been carried out with respect to system parameters of Example 6.1. For this purpose, the effects of the changes of the system parameters $\beta_{j}, \theta, \delta, \xi$ and $P$ from $-20 \%$ to $+20 \%$ on the optimal policy have been studied. The corresponding computational results have been displayed in Tables $4-8$. 
TABLE 3. Comparison of optimal results of three numerical examples.

\begin{tabular}{llll}
\hline \hline Objective function /decision variable & Example 6.1 & Example 6.2 & Example 6.3 \\
\hline Average profit, $\Pi\left(T^{*}\right)$ (in \$) & 14909.66 & 14891.08 & 10281.04 \\
Production period $\left(T^{*}\right)$ (in year) & 0.4276951 & 0.4005891 & 2.263442 \\
\hline
\end{tabular}

TABle 4. Post optimality analyses w.r.t. pre-payment parameters $\left(\beta_{j}\right)$.

\begin{tabular}{lllll}
\hline \hline $\begin{array}{l}\text { Pre-payment } \\
\text { parameters } \\
\left(\beta_{1}, \beta_{2}, \quad \beta_{3},\right.\end{array}$ & $\begin{array}{l}\text { Production } \\
\text { period }\left(T^{*}\right)\end{array}$ & $\begin{array}{l}\text { Total interest } \\
\text { earns due to } \\
\text { pre-payment }\end{array}$ & $\begin{array}{l}\text { Cost of free } \\
\text { transporta- } \\
\text { tion }\end{array}$ & $\begin{array}{l}\text { Average profit } \\
\Pi\left(T^{*}\right)\end{array}$ \\
\hline$-20 \%$ & $-6.15 \%$ & $-20 \%$ & $-97.00 \%$ & $+0.33 \%$ \\
$-10 \%$ & $-5.13 \%$ & $-10 \%$ & $-80.47 \%$ & $+0.32 \%$ \\
$+10 \%$ & $+20.05 \%$ & $+10 \%$ & $+219.54 \%$ & $-1.40 \%$ \\
$+20 \%$ & $+77.38 \%$ & $+20 \%$ & $+942.29 \%$ & $-5.53 \%$ \\
\hline
\end{tabular}

TABle 5. Post optimality analyses w.r.t. defective rate $(\theta)$.

\begin{tabular}{llll}
\hline \hline Defective rate $(\theta)$ & Production period $\left(T^{*}\right)$ & Disposal cost & Average profit $\left(\Pi\left(T^{*}\right)\right)$ \\
\hline$-20 \%$ & $-0.15 \%$ & $-20 \%$ & $+3.69 \%$ \\
$-10 \%$ & $-0.08 \%$ & $-10 \%$ & $+1.84 \%$ \\
$+10 \%$ & $+0.08 \%$ & $+10 \%$ & $-1.84 \%$ \\
$+20 \%$ & $+0.15 \%$ & $+20 \%$ & $-3.69 \%$ \\
\hline
\end{tabular}

TABLE 6. Post optimality analyses w.r.t. rework parameter $(\delta)$ and rework cost $\left(r_{c m}\right)$.

\begin{tabular}{llll}
\hline \hline $\begin{array}{l}\text { Rework parameters } \\
\left(\delta, r_{c m}\right)\end{array}$ & $\begin{array}{l}\text { Production period } \\
\left(T^{*}\right)\end{array}$ & Disposal cost & $\begin{array}{l}\text { Average profit } \\
\Pi\left(T^{*}\right)\end{array}$ \\
\hline$-20 \%$ & $+1.40 \%$ & $+180 \%$ & $-5.79 \%$ \\
$-10 \%$ & $+0.69 \%$ & $+90 \%$ & $-2.77 \%$ \\
$+10 \%$ & $-0.68 \%$ & $-89.98 \%$ & $+2.52 \%$ \\
\hline
\end{tabular}

TABLE 7. Post optimality analyses w.r.t. production rate $(P)$.

\begin{tabular}{lll}
\hline \hline Production rate $(P)$ & Production period $\left(T^{*}\right)$ & Average profit $\left(\Pi\left(T^{*}\right)\right)$ \\
\hline$-20 \%$ & $11.8 \%$ & $-20.57 \%$ \\
$-10 \%$ & $5.41 \%$ & $-10.30 \%$ \\
$+10 \%$ & $-4.65 \%$ & $+10.31 \%$ \\
$+20 \%$ & $-8.71 \%$ & $+20.65 \%$ \\
\hline
\end{tabular}


TABLE 8. Post optimality analyses w.r.t. transportation parameter $(\xi)$.

\begin{tabular}{llll}
\hline \hline $\begin{array}{l}\text { Transportation } \\
\text { parameter }(\xi)\end{array}$ & Transportation cost & $\begin{array}{c}\text { Production period } \\
\left(T^{*}\right)\end{array}$ & $\begin{array}{c}\text { Average profit } \\
\left(\Pi\left(T^{*}\right)\right)\end{array}$ \\
\hline$-20 \%$ & $+120.11 \%$ & $+8.14 \%$ & $-0.59 \%$ \\
$-10 \%$ & $+48.18 \%$ & $+3.20 \%$ & $-0.23 \%$ \\
$+10 \%$ & $-32.23 \%$ & $-2.09 \%$ & $+0.15 \%$ \\
$+20 \%$ & $-53.86 \%$ & $-3.46 \%$ & $+0.25 \%$ \\
\hline
\end{tabular}

From Tables 4-8, the following observations can be made:

- From Table 4, it is clear that the average profit has slightly reverse effect with the changes of pre-payment parameters $\left(\beta_{1}, \beta_{2}, \beta_{3}, \beta_{4}, \beta_{5}\right)$. On the other hand, the production period and transportation cost have largely direct effective with the changes of $\beta_{1}, \beta_{2}, \beta_{3}, \beta_{4}$ and $\beta_{5}$. Also the amount of interest earned due to pre-payment equally sensitive directly with the changes of the same.

- Table 5 shows that the average profit has less sensitive reversely with respect to the change of defective rate $(\theta)$. Again, the production period has insensitive with respect to $\theta$. Also the disposal cost has equally sensitive directly against the change of $\theta$.

- From Table 6, it is seen that the average profit has slightly direct effect with respect to rework parameter $(\delta)$ and average rework cost $\left(r_{\mathrm{cm}}\right)$. On the other hand, the production period has slightly reverse effect and the disposal cost has largely reverse effect with the changes of $\delta, r_{\mathrm{cm}}$.

- From Table 7, it is observed that the average profit has direct impact equally due to the change of the production rate $(P)$. Also the production period has moderately reverse impact due to the change of $P$.

- From Table 8, it is clear that the transportation cost has reverse impact largely due to the change of the effective parameter of transportation cost $(\xi)$. On the other hand, the production period has less sensitive reversely and the average profit is less sensitive directly w.r.t. $\xi$.

\section{Practical implications}

Generally, any production process may not be fully perfect. The reasons behind this imperfectness are due to (i) machinery problem, (ii) low-quality raw-material, (iii) unskill worker, (iv) uninterrupted power supply etc. As a result, manufacturing firm produces perfect as well as imperfect units. This type of situation is observed in most of the manufacturing firms in third world countries. For example: Let a factory produce floor tiles. During production period, some of the produced tiles (e.g., scratched, disordered shape, etc.) are defective. The screening section of this factory separates perfect and imperfect tiles. A part of imperfect tiles has been repaired during the production period. After screening, the perfect tiles are transported to different retailer's showroom/warehouse with partial pre-payment. The manager of the factory will take the decision: what would be the length of the production cycle? This type of problem may be implemented in every tiles factory. The solved problem gives a managerial insight to the decision maker of any newly established supply chain system where single manufacturer and multi retailers are involved.

\section{Conclusions AND FUture RESEARCH}

To the best of our knowledge, very few research works have been done in the area of single-manufacture and multi-retailer supply chain system. In this study, only one manufacturer and multiple retailers based supply chain system with partial pre-payment has been considered. Generally, the production process of any manufacturing firm is not fully perfect. As a result, at the time of production, some defective items are also produced along with perfect product and manufacturer separates these items through screening process in order to remove defective products from the produced items. Also, a part of imperfect items has been reworked 
during production period at a cost to restore its original quality. Pre-payment based free transportation concept has been incorporated to the entire supply chain. Finally, a comparative study of the proposed model with partial pre-payment, fully prepayment and no prepayment policy have been considered by three different numerical examples. After this comparison it is concluded that the proposed model is more economical in case of partial pre-payment based free transportation policy.

The proposed work can also be extended for deteriorating items considering different types of deterioration rates that follow two-parameter Weibull distribution, three-parameter Weibull distribution, age dependent deterioration, etc. Also, the proposed work can be extended by considering different realistic factors such as fully/partially backlogged shortage, nonlinear demand, nonlinear holding cost, etc.

\section{Appendix A.}

In this section, the concavity of the objective function of (4.10) has been tasted analytically. The objective function of (4.10) is given by

$$
\begin{aligned}
\Pi(T)= & \frac{n P}{m+n}\left[s_{r}\{(1-\theta)+\theta \delta\}-\left\{c_{p}+s_{c}+r_{c m} \delta \theta+c_{d}(1-\delta) \theta\right\}\right]+s_{r} \sum_{j=1}^{r} \frac{I_{e}}{2 k_{j}} \beta_{j}\left(k_{j}-1\right) Q_{j} \\
& -\frac{h_{c}}{2(m+n)^{2}}\{n+m(n+m-1)\}\{(1-\theta)+\theta \delta\} P T-\frac{n c_{t}}{T} \sum_{j=1}^{r} \beta_{j}^{\xi} d_{m j} Q_{j}-\frac{n^{2} A}{(m+n) T} .
\end{aligned}
$$

Now the first and second order derivatives of (A.1) with respect to $T$ are given by

$$
\begin{aligned}
\frac{\mathrm{d}}{\mathrm{d} T}\{\Pi(T)\} & =-\frac{h_{c}}{\{\sqrt{2}(m+n)\}^{2}}\{n(m+1)+m(m-1)\}\{(1-\theta)+\theta \delta\} P+\frac{n c_{t}}{T^{2}} \sum_{j=1}^{r} \beta_{j}^{\xi} d_{m j} Q_{j}+\frac{n^{2} A}{(m+n) T^{2}} \\
\frac{\mathrm{d}^{2}}{\mathrm{~d} T^{2}}\{\Pi(T)\} & =-\frac{2 n}{T^{3}}\left\{c_{t} \sum_{j=1}^{r} \beta_{j}^{\xi} d_{m j} Q_{j}+\frac{n A}{m+n}\right\} .
\end{aligned}
$$

Clearly, $\frac{\mathrm{d}^{2}}{\mathrm{~d} T^{2}}\{\Pi(T)\}$ is negative.

Therefore, $\Pi(T)$, the objective function of (4.10) is concave.

Lemma A.1. In the proposed problem, order quantity of all retailers in each cycle $(Q)$ can be expressed in terms of manufacturer's production period $(T)$ and production rate $(P)$.

$$
\text { i.e., } Q=\frac{1}{(m+n)}(P-\theta P+\delta \theta P) T \text {. }
$$

Proof. As per assumptions, manufacturer's production period and production rate are respectively $T$ and $P$. Manufacturer produces imperfect items at a rate $\theta P$ respectively. A part of the imperfect items is repaired at a rate $\delta \theta P$. So, the total amount of perfect items during the production period is $(P-\theta P) T+\delta \theta P T$. As the order quantity of all retailers in each cycle is $Q$, therefore,

$$
\begin{aligned}
(m+n) Q & =(P-\theta P) T+\delta \theta P T \\
Q & =\frac{1}{m+n}(P-\theta P+\delta \theta P) T .
\end{aligned}
$$

This completes the proof. 
Acknowledgements. The authors express their sincere thanks to the editor and the anonymous reviewers for their valuable and constructive comments and suggestions which have led to a significant improvement of the manuscript. The first author would like to thank University Grants Commission for providing the Dr. D.S. Kothari Post Doctoral Fellowship (DSKPDF) through The University of Burdwan to accomplish this research (Vide Research Grant No. F.4-2/2006. $(\mathrm{BSR}) / \mathrm{MA} / 18-19 / 0023)$.

\section{REFERENCES}

[1] H.K. Alfares and A.M. Ghaithan, EOQ and EPQ production-inventory models with variable holding cost: state-of-the-art review. Arab. J. Sci. Eng. 44 (2019) 1737-1755.

[2] M. Ben-Daya and M. Hariga, Economic lot scheduling problem with imperfect production processes. J. Oper. Res. Soc. 51 (2000) 875-881.

[3] A.K. Bhunia and A.A. Shaikh, A deterministic model for deteriorating items with displayed inventory level dependent demand rate incorporating marketing decisions with transportation cost. Int. J. Ind. Eng. Comput. 2 (2011) 547-562.

[4] A.K. Bhunia and A.A. Shaikh, A deterministic inventory model for deteriorating items with selling price dependent demand and three-parameter Weibull distributed deterioration. Int. J. Ind. Eng. Comput. 5 (2014) 497-510.

[5] A.K. Bhunia and A.A. Shaikh, An application of PSO in a two-warehouse inventory model for deteriorating item under permissible delay in payment with different inventory policies. Appl. Math. Comput. 256 (2015) 831-850.

[6] A.K. Bhunia, A.A. Shaikh and L.E. Cárdenas-Barrón, A partially integrated production-inventory model with interval valued inventory costs, variable demand and flexible reliability. Appl. Soft Comput. 55 (2017) 491-502.

[7] L.E. Cárdenas-Barrón, On optimal batch sizing in a multistage production system with rework consideration. Eur. J. Oper. Res. 196 (2009) 1238-1244.

[8] K.-J. Chung, The integrated inventory model with the transportation cost and two-level trade credit in supply chain management. Comput. Math. Appl. 64 (2012) 2011-2033.

[9] B.C. Das, B. Das and S.K. Mondal, Optimal transportation and business cycles in an integrated production-inventory model with a discrete credit period. Transp. Res. E Logist. Transp. Rev. 68 (2014) 1-13.

[10] A. Diabat, A.A. Taleizadeh and M. Lashgari, A lot sizing model with partial downstream delayed payment, partial upstream advance payment, and partial back ordering for deteriorating items. J. Manuf. Syst. 45 (2017) 322-342.

[11] S.K. Goyal and L.E. Cárdenas-Barrón, Economic production quantity with imperfect production system. Ind. Eng. J. 34 (2005) 33-36.

[12] P.A. Hayek and M.K. Salameh, Production lot sizing with the reworking of imperfect quality items produced. Prod. Plan. Control 12 (2001) 584-590.

[13] C. Howard and J. Marklund, Evaluation of stock allocation policies in a divergent inventory system with shipment consolidation. Eur. J. Oper. Res. 211 (2011) 298-309.

[14] S. Jain, S. Tiwari, L.E. Cárdenas-Barrón, A.A. Shaikh and S.R. Singh, A fuzzy imperfect production and repair inventory model with time dependent demand, production and repair rates under inflationary conditions. RAIRO:OR 52 (2018) 217-239.

[15] M.A.A. Khan, A.A. Shaikh, G.C. Panda and I. Konstantaras, Two-warehouse inventory model for deteriorating items with partial backlogging and advance payment scheme. RAIRO:OR 53 (2018) 1691-1708.

[16] C. Krishnamoorthi and S. Panayappan, An EPQ model for an imperfect production system with rework and shortages. Int. J. Oper. Res. 17 (2013) 104-124.

[17] R. Levi, R. Roundy, D. Shmoys and M. Sviridenko, A constant approximation algorithm for the one-warehouse multi-retailer problem. Manage. Sci. 54 (2008) 763-776.

[18] R. Li, Y.-L. Chan, C.-T. Chang and L.E. Cárdenas-Barrón, Pricing and lot-sizing policies for perishable products with advancecash-credit payments by a discounted cash-flow analysis. Int. J. Prod. Econ. 193 (2017) 578-589.

[19] C.-S. Lin, C.-H. Chen and D.E. Kroll, Integrated production-inventory models for imperfect production processes under inspection schedules. Comput. Ind. Eng. 44 (2003) 633-650.

[20] R. Mallick, A.K. Manna and S.K. Mondal, A supply chain model for imperfect production system with stochastic lead time demand. J. Manage. Anal. 5 (2018) 309-333.

[21] A.K. Manna, J.K. Dey and S.K. Mondal, Controlling GHG emission from industrial waste perusal of production inventory model with fuzzy pollution parameters. Int. J. Syst. Sci. Oper. Logist. 6 (2018) 368-393.

[22] A.K. Manna, J.K. Dey and S.K. Mondal, Effect of inspection errors on imperfect production inventory model with warranty and price discount dependent demand rate. RAIRO:OR 54 (2020) 1189-1213.

[23] A.H. Nobil, A.H.A. Sedigh and L.E. Cárdenas-Barrón, A generalized economic order quantity inventory model with shortage: case study of a poultry farmer. Arab. J. Sci. Eng. 44 (2018) 2653-2663.

[24] L.-Y. Ouyang and C.-T. Chang, Optimal production lot with imperfect production process under permissible delay in payments and complete backlogging. Int. J. Prod. Econ. 144 (2013) 610-617.

[25] S. Pal and G.S. Mahapatra, A manufacturing-oriented supply chain model for imperfect quality with inspection errors, stochastic demand under rework and shortages. Comput. Ind. Eng. 106 (2017) 299-314.

[26] M.J. Rosenblatt and H.L. Lee, Economic production cycles with imperfect production process. IIE Trans. 18 (1986) $48-55$.

[27] M.K. Salameh and M.Y. Jaber, Economic production quantity model for items with imperfect quality. Int. J. Prod. Econ. 64 (2010) 59-64. 
[28] S.S. Sana, An economic production lot size model in an imperfect production system. Eur. J. Oper. Res. 201 (2010) 158-170.

[29] S.S. Sana, A production-inventory model of imperfect quality products in a three-layer supply chain. Decis. Support Syst. 50 (2011) 539-547.

[30] B. Sarkar, An inventory model with reliability in an imperfect production process. Appl. Math. Comput. 218 (2012) $4881-4891$.

[31] B. Saroglu and E.A.Durmus, Manufacture and testing of air springs used in railway vehicles. Arab. J. Sci. Eng. 44 (2019) 7967-7977.

[32] N.H. Shah, M.Y. Jani and U. Chaudhari, Optimal replenishment time for retailer under partial upstream prepayment and partial downstream overdue payment for quadratic demand. Math. Comput. Model. Dyn. Syst. 24 (2017) 1-11.

[33] A.A. Shaikh, S.C. Das, A.K. Bhunia, G.C. Panda and M.A.A. Khan, A two-warehouse EOQ model with interval-valued inventory cost and advance payment for deteriorating item under particle swarm optimization. Soft Comput. 23 (2019) 1353113546.

[34] A.A. Shaikh, L.E. Cárdenas-Barrón, A.K. Bhunia and S. Tiwari, An inventory model of a three parameter Weibull distributed deteriorating item with variable demand dependent on price and frequency of advertisement under trade credit. RAIRO: OR 53 (2019) 903-916.

[35] C.C. Sherbrooke, A multi-echelon technique for recoverable item control. Oper. Res. 16 (1968) $122-141$.

[36] P. Supakar and S.K. Mahato, Fuzzy-stochastic advance payment inventory model having no shortage and with uniform demand using abc algorithm. Int. J. Appl. Comput. Math. 4 (2018) 107.

[37] A.A. Taleizadeh, Lot-sizing model with advance payment pricing and disruption in supply under planned partial backordering. Int. Trans. Oper. Res. 24 (2017) 783-800.

[38] A.A. Taleizadeh, D.W. Pentico, M.S. Jabalameli and M. Aryanezhad, An economic order quantity model with multiple partial prepayments and partial backordering. Math. Comput. Model. 57 (2013) 311-323.

[39] J.T. Teng, L.E. Cárdenas-Barrón, H.J. Chang, J. Wu and Y. Hu, Inventory lot-size policies for deteriorating items with expiration dates and advance payments. Appl. Math. Model. 40 (2016) 8605-8616.

[40] S. Tiwari, A.H. Nobil and L.E. Cárdenas-Barrón, Note on Multiproduct single-machine production system with stochastic scrapped production rate, partial backordering and service level constraint. Int. J. Appl. Comput. Math. 5 (2019) 83.

[41] W. Yang, F.T.S. Chan and V. Kumar, Optimizing replenishment polices using Genetic Algorithm for single-warehouse multiretailer system. Expert Syst. Appl. 39 (2012) 3081-3086.

[42] J. Yu, B.R. Sarker, Q. Duan and B. Wu, Single-manufacturer, multi-retailer consignment policy for retailers' generalized demand distributions. J. Oper. Res. Soc. 63 (2012) 1708-1719.

[43] A.X. Zhang, Optimal advance payment scheme involving fixed per-payment costs. Omega 24 (1996) $577-582$. 